\title{
Value of quantitative nucleolar features in the preoperative cytological diagnosis of follicular neoplasias of the thyroid
}

\author{
R Montironi, A Braccischi, M Scarpelli, G Matera, R Alberti
}

\begin{abstract}
Nucleolar prevalence, size, and outline were investigated on cytological material from cold thyroid nodules obtained by fine needle aspiration. The percentage of nucleolated nuclei in follicular adenoma (32 cases) was less than in follicular carcinoma (26 cases). In adenoma most nuclei contained one nucleolus, and nuclei with two or more nucleoi were less common than in carcinoma where most cases showed the highest nucleolar diameter values. There was some overlap between adenomas and carcinomas, however, when the mean of the 10 largest values of the major nucleolar diameter was considered. In follicular carcinoma the percentage of marginated nucleoli-that is, those touching the nuclear membrane-was, in general, greater than $20 \%$; in adenoma the values were equal to or lower than $16 \%$.

The overlap index showed that the percentages of marginated nucleoli and nucleolated nuclei are the two best discriminatory features between adenoma and carcinoma.
\end{abstract}

The role of cytopathology, and in particular fine needle aspiration biopsy in the diagnosis of follicular lesions of the thyroid is highly controversial. Some say that it is impossible to differentiate between follicular adenoma and carcinoma; others believe that refinement of the cytological diagnosis gives the cytopathologist more confidence in identifying follicular carcinoma. ${ }^{1-12}$ For instance, Suen proposed the semiquantitative analysis of several cytological features for distinguishing groups of follicular lesions according to their probability of malignancy. ${ }^{13}$ She pointed out that the evaluation of some cell features or components, such as nucleoli, have more discriminatory value than others, such as the nuclear size and outline. Other authors also included the evaluation of nucleoli among the cytopathological features for the identification of benign and malignant follicular lesions. ${ }^{7-9}$ Because a cytological feature in one group overlaps with that in another group and because the evaluation is routinely performed on a purely subjective basis, however, the validity of the identification of follicular adenoma and follicular carcinoma has not proved to be as good as that of other thyroid carcinomas, such as the papillary, medullary, and anaplastic variants. ${ }^{161014}$
During the past few years the quantitative analysis of cytological features has been tested to improve the accuracy of the discrimination between benign and malignant lesions. ${ }^{14-29}$ Even though there are some differences between these two broad categories, a disturbing overlap has been observed, thus reducing the potential routine application of quantitative methods to the cytological diagnosis of cold thyroid nodules, unless a discriminant analysis is applied. ${ }^{26}$

The aims of this study were (i) to quantify features related to the nucleolar prevalence, size, and margination in follicular adenoma and carcinoma using a routine microscope with an eyepiece with an incorporated horizontal micrometer; and (ii) to evaluate the importance of the nucleolar features in the differentiation of benign (adenoma) and malignant (carcinoma) lesions.

\section{Methods}

The study was carried out on cytological material from 58 cases of follicular neoplasia of the thyroid (cold nodules) obtained by fine needle aspiration biopsy. The specimens were included when at least two slides per case with a minimum of eight to 10 tissue fragments or clusters of cells obtained with multiple aspirations were available. By using a doubleheaded microscope, two of our team (RM and MS) reviewed the histological slides of the resected specimen and reached a common diagnosis in all the cases. In this way we were able to use the histological reports as a reference diagnosis for the 58 cases of follicular lesions: 32 follicular adenomas and 26 follicular carcinomas. Histologically the follicular carcinomas were all angioinvasive; tumours with an oxyphil appearance were not included. All smears had been wet-fixed in 95\% ethyl alcohol and stained according to a hypochromic Papanicolaou staining procedure, which visualises nucleoli and outlines the distribution of chromatin. Nucleoli appear more round than chromatin particles and have a regular contour. Of the two slides available in each case, the most cellular was selected for the quantitative study.

The nucleolar prevalence was evaluated blind using a Leitz Dialux 20 EB microscope at the final microscopic magnification of 1000 times (100 times objective magnification; 10 times ocular magnification; oil immersion) by one of us (AB). The evaluation was performed on 100 nuclei adopting the vertical stratified 


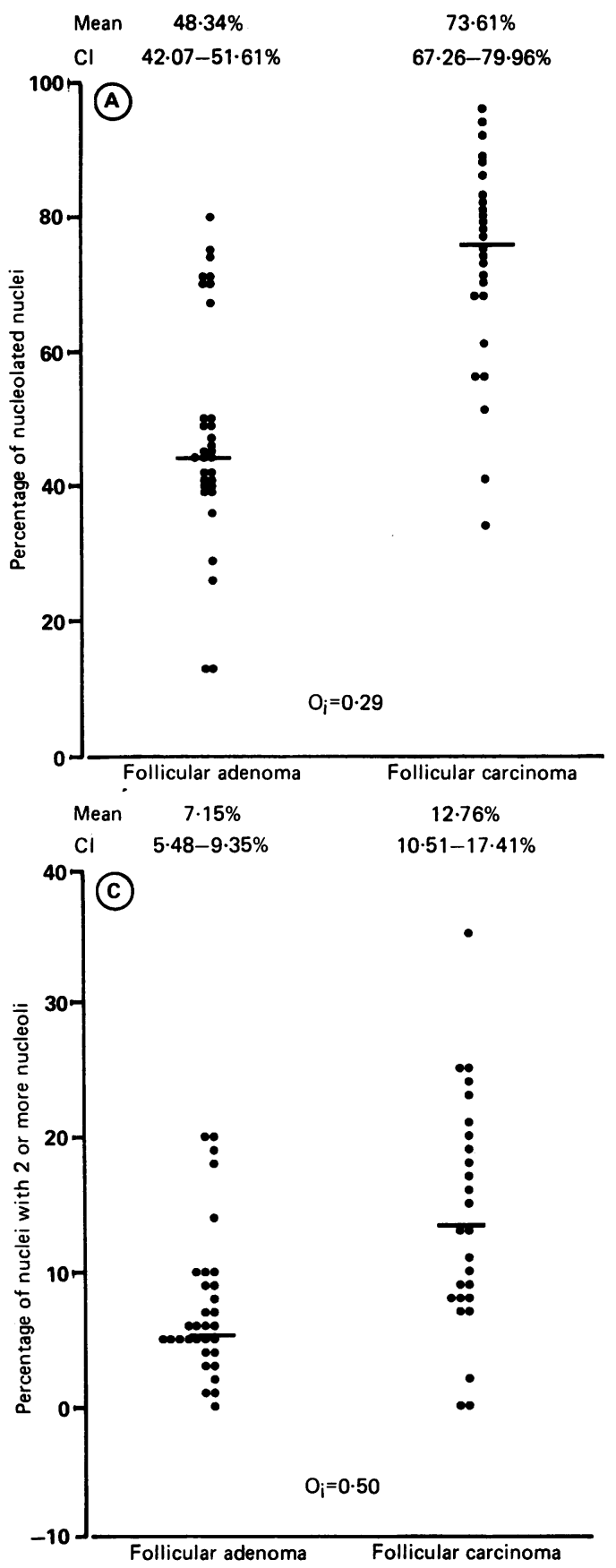

method and starting from one corner of the slide; from this point, parallel lines were scanned in the $y$ direction, with each successive line farther towards the end of the slide. Poorly stained, poorly fixed, and clotted nuclei were not evaluated. To visualise all the nucleoli present in each nucleus the microscope was focused more than once so as to scan the whole nucleus in depth.

The nucleolar size and outline were measured successively by the same observer who adopted the same type of selection rules and used the same microscope. The evaluations of nucleoli were performed at 1000 times magnification and the following two raw variables were determined in 100 nucleoli in areas of the slides corresponding to those in which the prevalence was evaluated: (i) major nucleolar diameter; and (ii) number of nucleoli touching the nuclear membrane. The raw diameter data were expressed in arbitrary

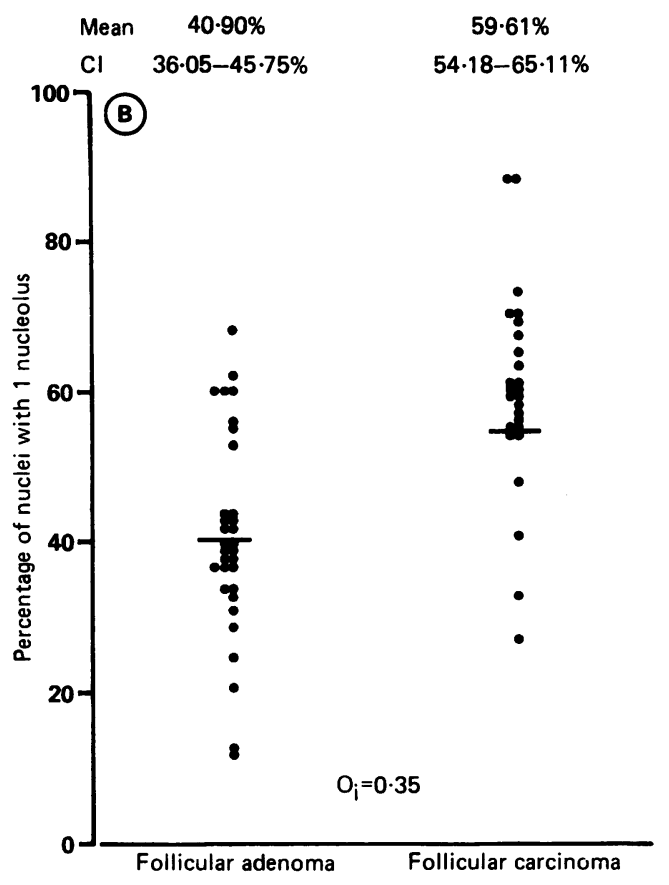

Figure 1 Scattergram to show the percentage of nucleolated nuclei $(A)$, of nuclei with one nucleolus ( $B$ and of nuclei with two or more nuceloli ( $C$ ) for each case examined. $O$, stands for overlap index; its values range from zero if there is no overlap to one if the observations from the two groups have the same medians. The lowest $O$ value was obtained for the percentage of nucleolated nuclei. Horizontal bars indicate the median for each group.

units (au), according to which 1 corresponds to the distance between two contiguous lines in the micrometer, 2 to the distance between three contiguous lines, and so on (one au corresponds to $0.581 \mu \mathrm{m}$ ). No nucleoli with a major diameter lower than 2 au-that is, about $1 \mu \mathrm{m}$-were observed. In each case the time required for all the countings and measurements was about 20 minutes. Reproducibility was tested by duplicate evaluations of the raw features in eight cases (four follicular adenomas and four follicular carcinomas), showing correlation coefficients of $\geq 0.95$. As shown by others, ${ }^{30} 100$ nuclei and 100 nucleoli represent an acceptable sample size for the evaluation of nucleolar quantitative variables.

The following features were derived:

Nucleolar features related to prevalence:

Percentage of nuclei with nucleoli $(\% \mathrm{NNu})$

Percentage of nuclei with one nucleolus $(\% \mathrm{NNu} 1)$, of nuclei with two or more nucleoli ( $\% \mathrm{NNu} 2) . \% \mathrm{NNu} 1$ and $\% \mathrm{NNu} 2$ were calculated in relation to the total number of nuclei (100) counted in each case.

Nucleolar features related to size:

Mean major nucleolar diameter (NuD; $\mu \mathrm{m})$

Mean of the 10 largest values of the major nucleolar diameters ( $10 \mathrm{NuD} ; \mu \mathrm{m})$

Features related to the shift of the nucleoli to the periphery of the nucleus (nucleolar margination)

Percentage of marginated nucleoli (\%MaNu)-that is, the percentage of nucleoli touching the nuclear membrane. 
Figure 2 Scattergram to show the mean of the major nucleolar diameter $(A)$ and the mean of the 10 largest values of the major nucleolar diameter ( $B$ ) for each case examined. $O$. stands for overlap index and indicates the degree of value overlap between follicular adenomas and follicular carcinomas. The lowest $O_{i}$ value was obtained for the major nucleolar diameter.

Horizontal bars indicate the median for each group.

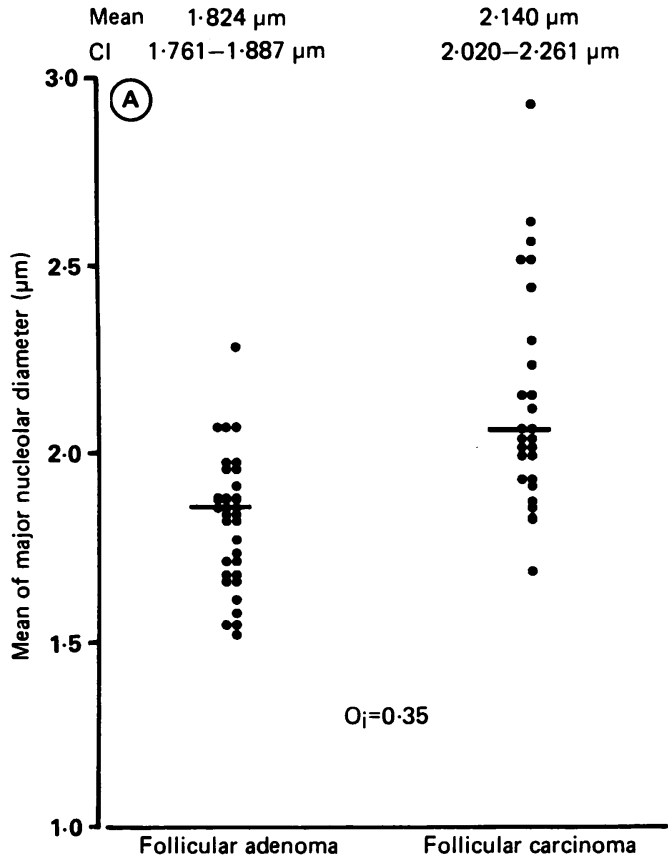

The overlap index $\left(\mathrm{O}_{\mathrm{i}}\right)$ was calculated for all the variables to quantify the degree of overlap between the two diagnostic categories and to identify those which permit the best differentiation of follicular adenomas from follicular carcinomas. It is a non-parametric index originally developed by $\mathrm{Hartz}^{31}$ for comparing the utility of a laboratory test.

$\mathrm{O}_{\mathrm{i}}$ is calculated as follows:

(a) Combine the $n_{1}$ observations from sample 1 and the $n_{2}$ observations from sample 2, and then rank all the observations from the smallest to the largest.

(b) For tied observations, first assign raw ranks to the tied values as if they were not tied. The corrected rank is the average of the raw ranks of the tied numbers.

(c) Add ranks for one of the samples, such as sample 1. Generally it is more convenient to add ranks for the smaller size sample. Call it sum of the ranks $T_{x}$.

(d) Calculate $\mathrm{T}_{\mathrm{y}}=\mathrm{n}_{1} \quad\left\{\left(\mathrm{n}_{1}+\mathrm{n}_{2}+1\right) / 2\right\}$. $T_{y}=T_{x}$ when the medians of the two samples are the same-that is, when there is complete overlap.

(e) Calculate $O_{i}=1-\left|\left\{\left[2\left(T_{x}-T_{y}\right)\right] / n_{1} n_{2}\right\}\right|$. The value of $O_{i}$ ranges from zero if there is no overlap to one if the observations from the two samples have the same medians.

The sum of the ranks was obtained using a Macintosh II computer whose statistical package contains a program for the MannWhitney U test.

\section{Results}

As for the nucleolar features related to prevalence, the follicular adenomas had mean category values lower than those of carcinoma. In follicular adenoma, out of $48.34 \%$ (SD $17.39 \%$; median $44.0 \%$; $95 \%$ confidence interval, 42.07 to $54.61 \%$ ) nucleolated nuclei, $\%$ NNul was $40.90 \%$ (SD $13.45 \%$; median $39.0 \%$; $95 \%$ CI 36.05 to $45 \cdot 75 \%$ ) and $\% \mathrm{NNu} 2$ was $7 \cdot 15 \%$ (SD $5.06 \%$; median $6.0 \% ; 95 \%$ CI

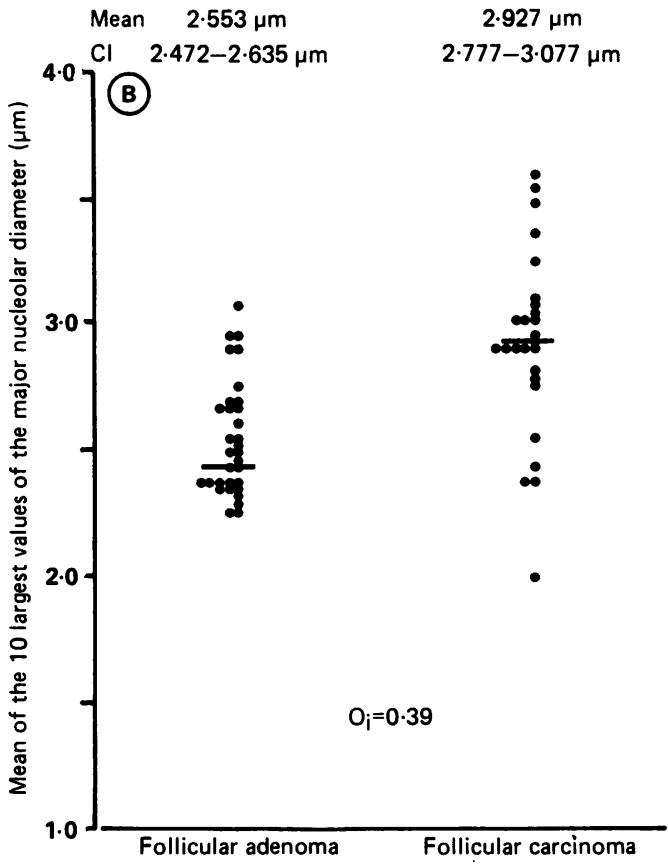

$5 \cdot 48$ to $9 \cdot 39 \%)$. In follicular carcinoma, out of $73.61 \%$ (SD $15.71 \%$; median $77.0 \%$; $95 \%$ CI 67.26 to $79.96 \%$ ) nucleolated nuclei, $59.61 \%$ (SD $15 \cdot 71 \%$; median $59.0 \%$; $95 \%$ CI 54.18 to $65.11 \%$ ) and $12.76 \%$ (SD $7 \cdot 62 \%$; median 13.0 ; $95 \%$ CI 10.51 to $17.41 \%$ ) of nuclei were mononucleolated and binucleolated or more, respectively (fig 1).

As for the mean major nucleolar diameter, the mean follicular adenoma category value was $1.824 \mu \mathrm{m}$ (SD $0.174 \mu \mathrm{m}$; median $1.853 \mu \mathrm{m}$; $95 \%$ CI 1.761 to $1.887 \mu \mathrm{m}$ )-that is, lower than in follicular carcinoma (mean $2.140 \mu \mathrm{m}$; SD $0.299 \mu \mathrm{m}$; median $2.045 \mu \mathrm{m} ; 95 \%$ CI 2.02 to $2.261 \mu \mathrm{m})$. Similarly, in follicular adenoma the mean of the 10 largest values of the major nucleolar diameter was $2.553 \mu \mathrm{m}$ (SD 0.226 $\mu \mathrm{m}$; median $2.5 \mu \mathrm{m}$; $95 \%$ CI 2.472 to 2.635 $\mu \mathrm{m}$ )- that is, lower than in follicular carcinoma

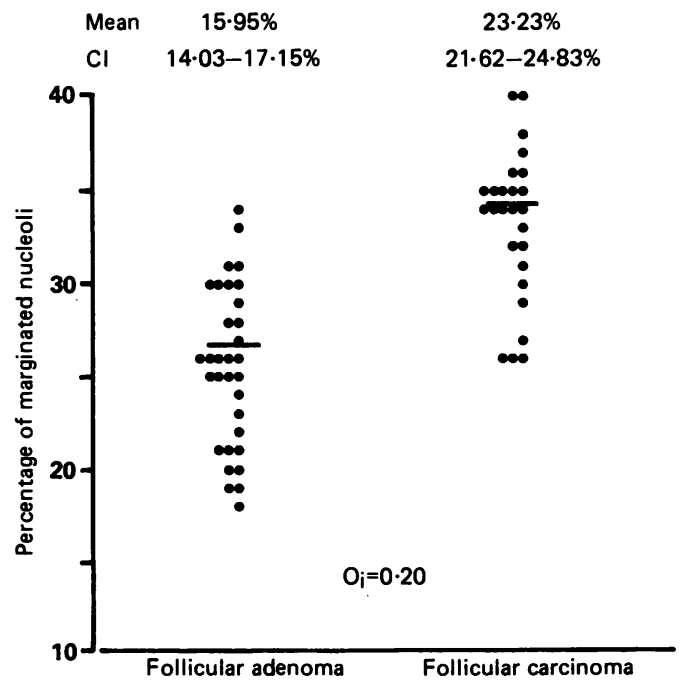

Figure 3 Scattergram to show the percentage of marginated nucleoli for each case examined. $O_{i}$ stands for overlap index and indicates the degree of value overlap between follicular adenomas and follicular carcinomas. The $O_{i}$ was the lowest of any of the features investigated. Horizontal bars indicate the median for each group. 
Figure 4 Scatterplot of the two variables with the smallest $O_{i}$ - that is, $\% M a N u$ and $\% N u N$.

The continuous line

present on the plane of the graph was drawn so as to separate cases of follicular adenomas from follicular carcinomas as much as possible. One carcinoma (encircled on the scatterplot) is included among the follicular adenomas; three adenomas (arrowed) fall among the carcinomas.

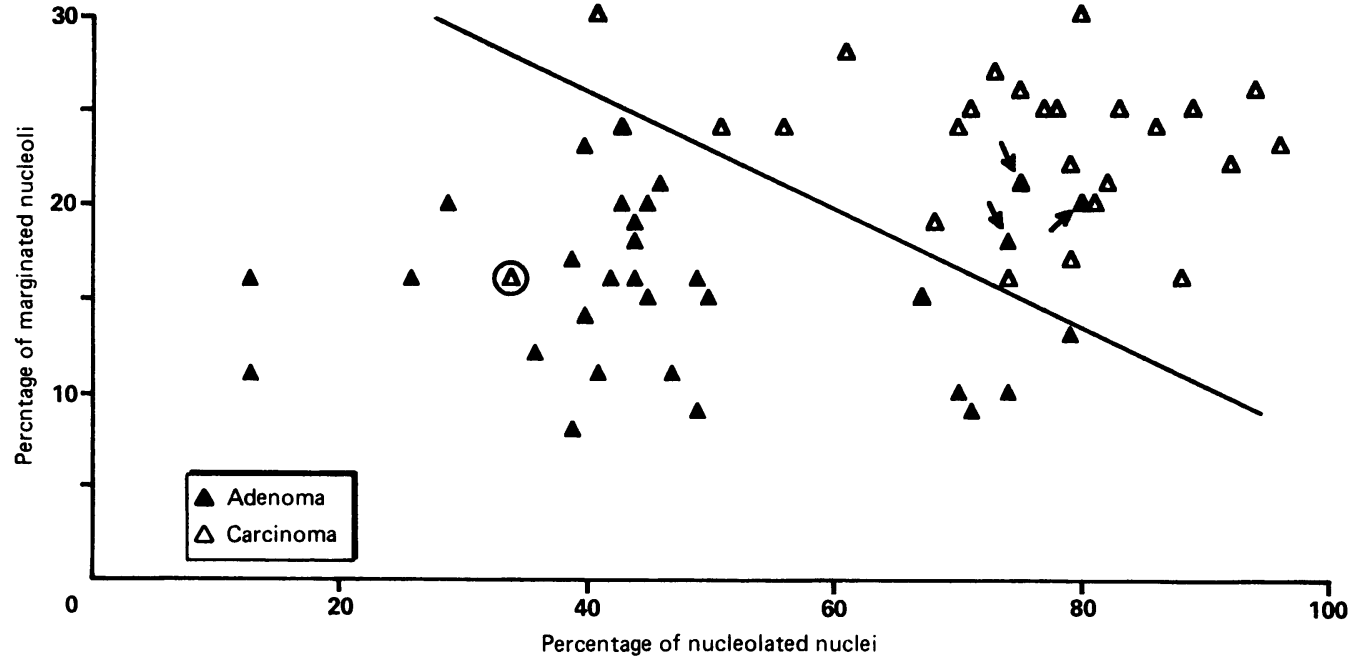

(mean 2.927 $\mu \mathrm{m}$; SD 0.371; median $2.92 \mu \mathrm{m}$; $95 \%$ CI 2.777 to $3.077 \mu \mathrm{m}$ ) (fig 2 ).

As for the percentage of marginated nucleoli, the mean category value obtained in follicular carcinoma was $23.23 \%$ (SD $3.97 \%$; median $24.0 \% ; 95 \%$ CI 21.62 to $24.83 \%$ )-that is, higher than in follicular adenoma, in which the mean was $15.95 \%$ (SD $4.33 \%$; median $16.0 \%$; $95 \%$ CI 14.03 to $17 \cdot 15 \%$ ) (fig 3 ).

Even though values related to prevalence, size, and margination were in general greater in follicular carcinoma than in follicular adenoma, there was no clear-cut separation between cases of follicular adenoma and follicular carcinoma on the basis of single feature analysis. Therefore, the overlap index was applied to identify the features with the smallest overlap. The test showed that the $\mathrm{O}_{i}$ values of the percentage of marginated nucleoli and of the percentage of nucleolated nuclei are the smallest - that is, 0.20 and 0.29 , respectively. For the other features the $\mathrm{O}_{i}$ values were as follows: \%NNul and NuD: $0.35 ; 10 \mathrm{HNuD}$ : $0 \cdot 39 ; \% \mathrm{NNu} 2: 0 \cdot 50$. The scatterplot of the two variables with the smallest $\mathrm{O}_{i}$-that is, $\% \mathrm{MaNu}$ and \% $\mathrm{NuN}$ (Spearman's rank correlation coefficient $0.38, \mathrm{p}<0.01$ ) is shown in fig 4 . The continuous line present on the plane of the graph was arbitrarily drawn to separate cases of follicular adenoma from follicular carcinoma as much as possible. One out of 26 carcinomas (encircled on the scatterplot) however, is included among the follicular adenomas, with three out of 32 adenomas (arrowed) among the carcinomas.

\section{Discussion}

Our quantitative study of nucleolar features on cytological preparations shows that prevalence, size, and outline are generally greater in follicular carcinoma than in follicular adenoma, and that good distinction between adenomas and carcinomas is achieved with the two variables having the smallest overlap index valuethat is, the percentage of marginated nuceloli and the percentage of nucleolated nuclei.

As for the nucleolar prevalence, two subgroups of qualitative terms are used in cytopathology practice. ${ }^{7-913}$ The first, which corresponds to our feature "percentage of nucleolated nuclei," includes terms such as "nucleoli absent, infrequent, inconsistent, always present." The other, which corresponds to the percentages of nuclei with one, two, or more nucleoli, includes terms such as "single or multiple." According to some authors, ${ }^{7-913}$ both subgroups are important in distinguishing follicular lesions of various types. In benign cases, in fact, nucleoli are in general infrequent and single; in carcinoma they are always present and multiple. In a previous paper we analysed quantitatively the nucleolar prevalence in benign and malignant thyroid neoplasias of several types and we found that nuclei in the carcinoma groups are frequently nucleolated with percentages of two or more nuclei greater than in non-cancer groups. ${ }^{25} \mathrm{It}$ was also observed that features associated with nucleolar prevalence have more discriminatory value than nuclear features, including the integrated optical density or DNA content. Van Diest et al investigated the prognostic value of quantitative nucleolar features in cytological material from breast cancers. ${ }^{30}$ Their results also suggested that nucleolar morphometric variables have a discrimination value exceeding that of nuclear variables and that the number of nucleoli per 100 nuclei was the best single variable.

As for nucleolar size, qualitative terms whose use in subjective cytological evaluation has been suggested, ${ }^{7-913}$ are "small, hypertrophic, prominent nucleoli, macronucleoli." Small nucleoli are currently observed in benign nodules; hypertrophic, prominent nucleoli (macronucleoli) are a common feature of malignant cases. Our features related to the nucleolar diameter quantified this observation. In particular, the mean of the 10 largest values of the major nucleolar diameter, selected on the basis of the results of the study by Huntington et al ${ }^{32}$ in which the malignancy potential of 100 intraocular melanomas was assessed with a micrometer technique, can be considered the quantitative equivalent of prominence. Similarly, according to Kelemen et al's study to identify nucleolar prominence as a diagnostic variable in prostatic carcinoma, ${ }^{33}$ "nucleoli appeared to be prominent . . . when the largest 
nucleolar diameter was $3 \mu \mathrm{m}$ or greater." In our present investigation we did not set any threshold for "prominent" nucleoli. The value suggested by Kelemen et al, however, ${ }^{33}$ is close to the median observed for follicular adenoma $(2.5 \mu \mathrm{m})$ and follicular carcinoma $(2.92 \mu \mathrm{m})$ when considering the variable mean of the 10 largest values of the major nucleolar diameter.

The nucleolus can move within the nucleus and in states of active protein synthesis it may come to lie against the nuclear membrane. This phenomenon is referred to as nucleolar margination. ${ }^{34}$ Although an occasional marginated nucleolus may be found in normal cells of any tissue, margination is seen much more frequently in cells rapidly growing or engaged in the production of a protein-rich secretion. For example, intense protein synthesis activity occurs in the regenerating liver after partial hepatectomy, in which some $50 \%$ of the nucleoli move to the nuclear margin. ${ }^{35}$ Ghadially observed that nucleolar margination occurs during the growth phase of the keratoacantoma. ${ }^{34}$ This type of nucleolar arrangement, however, is more frequently seen in a variety of malignant tumours-for instance, the adenocarcinoma of the prostate, carcinoma of the breast, and lymphomas. ${ }^{36} 37$ To the best of our knowledge, the change in position of the nucleolus in the nucleus in relation to the malignancy has not been previously included among the morphological criteria for the cytological diagnosis of thyroid nodules in material obtained by fine needle aspiration biopsy. In this study the nucleolar margination could be considered a feature indicative of malignancy. In fact, the percentages of marginated nuclei in follicular carcinomas are in general greater than in follicular adenomas, the value overlap between benign and malignant cases being lower than with the other "nucleolar" features. In a study on cells obtained from paraffin wax embedded material, ${ }^{38}$ the eccentricity-that is, a feature associated with location, was not helpful in cell classification. We do not have a definitive explanation for the discrepancy with our results, because the formula for the calculation of the eccentricity was not given and it was not specified whether the variable was measured in round as well as non-round nuclei. ${ }^{38}$ The percentage of marginated nuclei, in our opinion, however, is a feature which is easy to evaluate in all nuclei without taking into consideration the prerequisite for nucleolar eccentricity-that is, that the nucleus has to be round. Our data on nucleolar location are similar to those obtained on cytological specimens of hyperplastic and neoplastic prostatic lesions by Helpap ${ }^{37}$ : the percentage of peripherally located nucleoli in carcinoma was greater than in benign cases. We have not investigated the proportion of nucleoli in the central and intermediate positions. On a purely subjective basis, however, we observed that in benign thyroid lesions most of the nucleoli are not centrally located as in the prostate. This observation had yet to be confirmed quantitatively.

The overlap index adopted in our study helped us to identify the two nucleolar features which show the smallest overlap. Their combination in a scatterplot gives an idea of the spatial distribution of the cases and of the good differentiation of follicular adenomas from follicular carcinomas. On the divison made by the continuous line drawn on the graph (fig 4), a case of carcinoma is included among the adenomas. The corresponding histological slides were examined again. It was observed that, from the morphological point of view, the case was not homogeneous, but showed areas with well formed follicles, similar to those of colloid adenomas, together with areas having a trabecular pattern. Three adenomas fell in the part of the graph plane occupied by the carcinomas. Their prevalent histological architecture was that of a microfollicular or trabecular (cellular) pattern, as generally observed in our cases of follicular carcinomas.

In conclusion, our results agree with the concept that nucleolar changes may be characteristic of cancer cells in general ${ }^{39}$ and with Barigozzi et al's ${ }^{40}$ proposal that nucleolar abnormalities should be used in the identification of cancer cells. These changes, even though not specific for neoplasia, have been regarded as an expression of "the level of production of RNA in the nucleolus and the cytoplasmic demand for RNA" ${ }^{39}$ In particular, regarding nucleolar margination, Oberling and Bernhard stated that "one can assume that transportation of nucleolar products towards the cytoplasm is highly facilitated by this arrangement." 41 From the practical point of view, values for all features were greater in carcinoma than in adenoma. Nevertheless, the overlap between the two groups, even when data are combined, seems to limit an immediate diagnostic application for the technique. Studies are needed to identify either further cytological quantitative features or other multivariate analyses to avoid the overlap.

1 Akerman M, Tennvall J, Biorklund A, Moller T. Sensitivity and specificity of fine needle aspiration cytology in the diagnosis of tumours of the thyroid gland. Acta Cytol 1985;29:850-5.

2 Dominguez-Malagon H, Szymanski-Gomez J, GaytanGarcia S. Optically clear and vacuolated nuclei. Two useful signs of the transoperative diagnosis of papillary carcinomas of the thyroid. Cancer 1988;62:105-8.

3 Frable WJ, Frable MA. Fine needle biopsy of thyroid: histopathological and clinical correlations. In: Fenoglio CM, Wolff M, eds. Vol 1 Progress in surgical pathology. New York: Masson Publishing 1980:105-18.

4 Hall TL, Layfield LJ, Philippe A, Rosenthal DL. Sources of diagnostic error in fine needle aspiration of the thyroid. Cancer 1989;63:718-25.

5 Hamburger J, Husain M, Nishiyama R, Nunez C, Solomon $\mathrm{D}$. Increasing the accuracy of fine needle biopsy for thyroid D. Increasing the accuracy of fine needle biopsy for
nodules. Arch Pathol Lab Med 1989;113:1035-41.

6 Hawkins F, Bellido D, Bernal C, et al. Fine needle aspiration biopsy in the diagnosis of thyroid cancer and thyroid disease. Cancer 1987;59:1206-9.

7 Kini SR. Guides to clinical aspiration biopsy: Thyroid. Tokyo: Igaku-Shoin, 1987

8 Kline TS. Handbook of fine needle aspiration biopsy cytology. St Louis: C V Mosby, 1981.

9 Lowhagen T, Linsk JA. Aspiration biopsy cytology of the thyroid gland. In: Linsk JA, Franzen S, eds. Clinical aspiration cytology. London: J B Lippincott Co, 1983: $61-83$.

10 Miller JM, Kini SR, Hamburger JI. The diagnosis of malignant follicular neoplasms of the thyroid by needle biopsy. Cancer 1985;55:2812-7.

11 Silverman JF, West RL, Larkin EW, et al. The role of fineneedle aspiration biopsy in the rapid diagnosis and management of thyroid neoplasma. Cancer 1986;57: managem $1164-70$.

12 Suen KC, Quenville NF. Fine needle aspiration biopsy c 
the thyroid gland: a study of 304 cases. J Clin Pathol 1983;36:1036-45.

13 Suen KC. How does one separate cellular follicular lesions of the thyroid by fine needle-aspiration biopsy? Diagn Cytopathol 1988;4:78-81.

14 Auer GU, Backdahl M, Forsslund GM, Askensten UG Ploidy levels in non-neoplastic and neoplastic thyroid cells. Analyt Quant Cytol Histol 1985;7:97-105.

15 Bondeson L, Bondeson A-G, Lindholm K, Ljungberg O, Tibblin S. Morphometric studies on nuclei in smears of Tibblin $\mathrm{S}$. Morphometric studies on nuclei in smears of fine aspirates from ox
Cytol $1983 ; 7: 437-40$.

16 Boon ME, Lowhagen T, Cordozo PL, Blonk DI, Kurver PJH, Baak JPA. Computation of preoperative diagnosis probability of follicular adenomas and carcinomas of the thyroid on aspiration smears. Analyt Quant Cytol Histol 1982;4:1-5.

17 Cervino JM, Paseyro P, Grosso O, Maggiotto S. La exploracion de la glandula tirodes y sus correlaciones anatomoclinicas. Ann Facultad Med 1962;41:128-43.

18 Christov K. Flow cytometric DNA measurements in human thyroid tumors. Virchows Arch (Pathol Anat) 1986; 51:255-63.

19 Graham AR, Payne CM. Quantitative light and electron microscopic correlations of nuclear features in papillary microscopic correlations of nuclear features in papillary Histol 1989;11:331-40.

20 Greenebaum E, Koss LG, Elequin F, Silver CE. The diagnostic value of flow cytometric DNA measurements in follicular tumors of the thyroid gland. Cancer 985;56:2011-8

21 Joensuu H, Klemi PJ, Eerola E. Diagnostic value of flow cytometric DNA determination combined with fine needle biopsy in thyroid tumors. Analyt Quant Cytol Histol 1987;9:328-34.

22 Lang W, Georgi A, Stavah G, Kienzle E. The differentiation of atypical adenomas and encapsulated follicular carcinomas of the thyroid gland. Virchows Arch (Cell Pathol 1980;385:125-41.

23 Lee T-K, Meyers RT, Bond MG, Marshall RB, Kardon B The significance of nuclear diameter in the biologic behavior of thyroid carcinomas: a retrospective study of 127 cases. Hum Pathol 1987;18:1252-6.

24 Luck JB, Mumaw VR, Frable WJ. Fine needle aspiration biopsy of thyroid. Differential diagnosis by Videoplan image analysis. Acta Cytol 1982;26:793-6.

25 Mariuzzi GM, Montironi R, Alberti R, Scarpelli M, Sisti S Possibilità dell'analisi quantitativa per la classificazione citologica ed istologica delle neoplasie follicolari papillifere della tiroide. In: Battelli $T$, Maltoni $C$, Vecch A, eds. Noduli e tumori della tiroide. Bologna: Monduzz Editore, 1988:87-99.

26 Mattfeldt T, Schurmann G, Feichter G. Stereology and flow-cytometry of well-differentiated follicular neoplasms of the thyroid gland. Virchows Arch (Pathol Anat) 1987;410:433-41.

27 Montironi R, Alberti R, Sisti S, Braccischi A, Scarpelli M Mariuzzi GM. Discrimination between follicular adenoma and follicular carcinoma of the thyroid: preoperative validity of cytometry in aspiration smears. Appl Pathol 1989;7:367-74.

28 Montironi R, Braccischi A, Scarpelli $M$, et al. The number of nucleoli in benign and malignant lesions: a useful of nucleoli in benign and malignant lesions: a useful
diagnostic sign in cytological preparations. Cytopathology 1990 (in press).

29 Sobrinho-Simoes MA, Goncalves V, Sousa-Le F, Cordoso $\mathrm{V}$. A morphometric study of nuclei, nucleoli and nuclear bodies in goiters and papillary thyroid carcinomas. Experientia 1977;33:1642-3.

30 van Diest PJ, Mouriquasid J, Schipper NW, Baak JPA Prognostic value of nucleolar morphometric variables in cytologic breast cancer specimens. $J$ Clin Pathol 1990;43:157-9.

31 Hartz AJ. Overlap index. An alternative to sensitivity and specificity in comparing the utility of a laboratory test. Arch Pathol Lab Med 1984;108:65-7.

32 Huntington A, Haugen P, Gamel J, McLean I. A simple cytologic method for predicting the malignant potential of intraocular melanoma. Path Res Pract 1989;185:631-4 of

33 Kelemen PR, Bushimann RJ, Weisz-Carrington P. Nucleolar prominence as a diagnostic variable in prostatic

34 Ghadially FN. Nucleus. In: Ghadially FN, ed. Ultrastructural pathology of the cell. A text atlas of physiological and pathological alterations in cell fine structure. London: Butterworths, 1975:1-93.

35 Swift H. Studies on nucleolar function. In: Zirkle RE, ed. Symposium on molecular biology. Chicago: University of Chicago Press, 1959:266

36 Lesty C, Raphael M, Chleq C, Binet J-P. Nucleolar topography of nuclei in histologic sections. Analyt Quant Cytol Histol 1990;12:242-50.

37 Helpap B. Observations on the number, size and localization of nucleoli in hyperplastic and neoplastic prostatic disease. Histopathology 1988;13:203-11.

38 Ferrer-Roca O, Ballester-Guardia E, Martin-Rodriquez JA Morphometric, densitometric and flow cytometric criteria for the automated classification of thyroid lesions. Analyt Quant Cytol Histol 1990;12:48-55.

39 Koss LG. Diagnostic Cytopathology and its histopathologic bases. 3rd ed. Philadelphia: J B Lippincott Co, 1979

40 Barigozzi NK et al. La cariologia nella diagnosi delle neoplasie. Torino: Minerva Medica, 1957.

41 Oberling GH, Bernhard W. The morphology of cancer cells: In: Brachet J, Mirsky AE, eds. The Cell. Vol 5. New York: Academic Press, 1961:405-10. 